\title{
Ação, Caráter e Determinismo Psicológico em Aristóteles e Alexandre
}

Marco Zingano

Alexander presents in his De fato XXVI - XXXII an argument for determinism based on the moral character or disposition the agent has which makes him to act in a determinate way. The response Alexander offers to such an argument appeals basically to the idea that the agent is still responsible for what he does because he was fully responsible for the acts that caused the acquisition of the character, although he now cannot act but in only one way. This response generates its own difficulties, for the assessment of which a new reading of Mantissa 22 and 23 is proposed.

Após ter apresentado os argumentos em prol do determinismo com base na cadeia de causas unificada do universo (De fato XXII-XXV), Alexandre apresenta um segundo bloco de argumentos igualmente em favor do determinismo, fundados desta vez na relação entre caráter e ação. Este segundo bloco compreende os capítulos XXVIXXXII do De fato. Ele contém uma digressão sobre presciência divina e adivinhação (XXX-XXXI), que vou deixar de lado; meu interesse principal é examinar em que sentido o caráter moral pode funcionar como um argumento suplementar para o determinismo nas ações e como Alexandre lida com esta dificuldade.

O problema entre ação e caráter é introduzido aqui como tendo sido proposto pelos proponentes do determinismo. No entanto, como veremos a seguir, tratase de uma dificuldade que tem origem no sistema ético aristotélico, da qual Alexandre estava perfeitamente consciente. É plausível supor que os estóicos tenham apresentado 
tal dificuldade a título de argumento ad peripateticos, mas não é necessário supor isso, pois Alexandre pode estar simplesmente desenvolvendo um argumento que ele próprio reconhece causar dificuldade internamente ao aristotelismo. O problema pode ser formulado do seguinte modo. No aristotelismo, para se poder atribuir responsabilidade moral ao agente, é preciso supor que o agente podia, em um sentido relevante, deixar de fazer o que fez. A possibilidade dos contrários quando estava a ponto de agir é condição necessária para a atribuição de responsabilidade moral; quando age, não pode mais deixar de fazer o que fez, mas, quando estava a ponto de agir, sempre podia ter agido diferentemente. Toda ação está assim aberta aos contrários. Contudo, à medida que o agente age de um modo e não de outro, ele adquire uma certa disposição de agir assim e não de outro modo. Virtudes e vícios são disposições morais; ora, como o próprio Aristóteles declara, a disposição não está mais aberta aos contrários, mas é somente de um deles, assim como, com base na saúde, produzem-se somente atos de saúde e não mais atos em direção contrária (cf. EN V 1 1129a13-17). Por conseguinte, o homem virtuoso, bem como o vicioso, não pode mais agir diferentemente; mas se é assim, com base em que podemos ainda atribuir-lhe responsabilidade moral, se esta supunha a possibilidade de agir diferentemente, o que lhe é agora expressamente negado?

O problema pode, portanto, ser formulado em termos estritamente aristotélicos. Ele foi reconhecido contemporaneamente como o da divisão da vida moral em dois momentos: em um primeiro o agente é disposicionalmente imaturo, mas livre, pois pode agir diferentemente; no segundo, para o qual tende natural e inapelavelmente, o agente tem suas disposições bem determinadas, mas não pode mais agir diferentemente. Alguns autores falaram, conseqüentemente, de uma "psicologia determinista”; embora Aristóteles quisesse defender uma tese da liberdade na escolha de cada ação, seu sistema o enclausurava em uma doutrina na qual as disposições inevitavelmente adquiridas pelo agente o faziam agir sempre de um mesmo modo. ${ }^{1}$ Em um tal sistema, porém, é o agente ainda responsável por suas ações, já que não lhe é

\footnotetext{
${ }^{1}$ Para D. Furley, "parece que temos uma distinção entre dois períodos na vida de um homem antes e depois da formação de seu caráter" (Two Studies in Greek Atomists, Princeton 1967, pp. 189-190); para usar uma expressão de J. Hintikka, Aristóteles teria um "self-inflicted determinism” (Aristotle on Modality and Determinism, Amsterdam 1977, p. 8).
} 
mais possível deixar de fazer o que faz? Vou chamar este problema de o paradoxo de Alexandre, pois podemos retraçar pelo menos até ele a aguda consciência desta dificuldade interna ao aristotelismo. Mais do que isso, a resposta que contemporaneamente se forneceu também se inspira fortemente na que forneceu Alexandre. Com efeito, a resposta que Alexandre sugeriu está baseada na idéia de transitividade da responsabilidade. A disposição provém dos atos realizados em uma certa direção; quando a tenho, não mais posso agir diferentemente, mas me foi possível agir diferentemente em relação aos atos que levaram à sua aquisição. A responsabilidade minha naqueles atos - pois em relação a eles sempre podia agir diferentemente - transfere-se ao meu atual estado disposicional, de modo que posso continuar a ser responsabilizado pelas minhas ações atuais, já que fui responsável pelos atos que geraram as atuais disposições. A passagem mais clara a este respeito encontrase em De fato XXVII: as disposições estão em meu poder, escreve Alexandre, na medida em que, antes de as ter adquiridas, estava em meu poder adquiri-las ou não

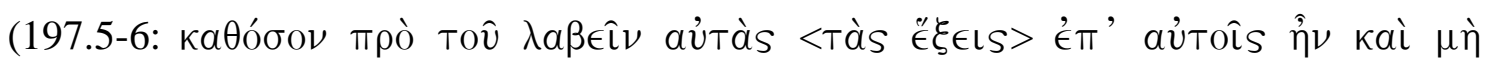
$\lambda \alpha \beta \in \hat{\imath} \nu$ ). Sou responsável em relação a este ato (que não mais posso fazer diferentemente) porque fui responsável pelos atos que me levaram à aquisição da atual disposição, e a respeitos destes últimos podia agir diferentemente. É esta mesma solução que é aventada modernamente.

Há aparentemente boas razões para se dar crédito a esta solução. Com efeito, a solução de Alexandre não deixa de ter estirpe aristotélica. De fato, Aristóteles comenta, a respeito de certos atos, como os de um embriagado, que, embora não esteja mais em poder de quem está ébrio agir diferentemente, estava em seu poder, contudo, tornar-se embriagado ou não, e por esta razão Aristóteles louva a atitude de Pítaco de Mitilene de dobrar a pena em tais casos (EN III 7 1113b30-33). ${ }^{2}$ Duas observações impõem-se, porém. Em primeiro lugar, estes casos de transferência são, em Aristóteles, limitados a situações em que, em conseqüência de certos atos, perde-se o domínio da razão, momentânea ou definitivamente. São casos, portanto, caracterizados muito

\footnotetext{
${ }^{2}$ A pena dobrada provém de uma lei atribuída a Pítaco, tirano de Mitilene no início do séc. VI; cf. IX 6 1167a32; Pol. II 12 1274b18-23; Rhet. II 25 1402b9-12.
} 
precisamente, quaisquer que seja sua freqüência, e sua caracterização não coincide com a dos atos virtuosos ou viciosos simpliciter, nos quais não há corrupção do uso da razão. seja momentânea ou definitiva. Em segundo lugar, como observou Irwin, “Aristóteles não supõe que sejamos responsáveis pela ação causada pela ignorância, mas somente que somos responsáveis pela ignorância que causou a ação”. ${ }^{3}$ Aristóteles distingue, na Ethica Nicomachea III 2, entre atos cometidos por ignorância e atos cometidos em estado de ignorância. No caso dos primeiros, quando a ignorância incidir sobre as circunstâncias nas quais se produz a ação, o ato é propriamente involuntário e problemas de responsabilização moral ficam conseqüentemente suspendidos. No caso dos segundos, embora não se possa considerar que agiu voluntariamente quem estava em estado de ignorância, o agente é responsável pelo entrar em estado de ignorância, e é esta responsabilidade que autoriza culpar quem age mal em tal estado, não suspendendo as questões de responsabilidade moral. Mesmo assim, Alexandre pretende expandir esta explicação para todos os atos realizados na fase madura de um agente, a saber, os atos baseados em disposições morais, e pretende que a transitividade garante não somente a responsabilidade pela aquisição das disposições, mas também pela realização dos atos que delas derivam, ainda que estes não possam mais ocorrer diferentemente.

Alexandre mesmo assim reintroduz certa flexibilidade quando, em $D e$ fato XXIX, examina o caso do homem prudente, aquele que não pode mais cometer nenhum ato vil. O prudente não pode mais cometer um ato vil porque não pode mais agir diferentemente, mas somente praticar atos moralmente bons, aqueles que decorrem de sua disposição moral boa. Para Alexandre, contudo, é possível que o prudente aja diferentemente em duas circunstâncias. Em primeiro lugar, (i) como toda ação comporta uma zona cinza mais ou menos maleável, o prudente pode agir diferentemente em relação a certos aspectos desta zona que não têm relevância moral (1999.31-200.2). Por exemplo, ele certamente acudirá à pessoa que está desmaiando no corredor, pois não pode agir de outro modo a este respeito, mas talvez ele saia da sala em que se encontra pelo lado esquerdo da mesa, ou pelo lado direito. Em segundo lugar, (ii) suponhamos

\footnotetext{
${ }^{3}$ T. Irwin, Nicomachean Ethics, Hackett 1985, p. 319.
} 
que um adivinho tenha predito o que fará o prudente; ora, ele pode em certas ocasiões não fazer o que se espera dele no intuito justamente de mostrar que possui liberdade em suas ações, desmentindo as predições a seu respeito (200.2-7). Em ambas as circunstâncias, o prudente agiria diferentemente, o que atestaria sua liberdade ainda fundada na abertura aos contrários. Parece claro, todavia, que ambas as exceções são insuficientes para constituir um domínio pleno de liberdade do agente maduro. $\mathrm{O}$ problema do primeiro caso é que a diferença na ação ocorre em aspectos sem relevância moral, quando o que está em questão são os aspectos com relevância moral de sua ação. Responsabilizamos alguém moralmente não porque saiu da sala pelo lado esquerdo ou pelo lado direito da sala, mas porque acudiu ou não acudiu a uma pessoa em necessidade. Alguém necessariamente irá à guerra para defender sua cidade, mas é incerto se portará uma lança vermelha, azul ou colorida - na verdade, pouco importa este detalhe, pois o que está em questão é se irá ou não à guerra, e isso ele fará, ou não fará, necessariamente, conforme a disposição que possuir em relação aos atos de coragem. Quanto ao segundo caso, a liberdade fica dependente de atos de bizarria do prudente, que deixa de fazer o que se espera dela no intuito de desfazer uma dada predição. Os elementos (i) e (ii) deveriam funcionar como indícios de uma liberdade de que ainda disporia o agente disposicionalmente caracterizado em relação aos contrários para cada ação, mas nem (i) nem (ii) nem a conjunção de (i) e (ii) é capaz de validar a existência de uma tal liberdade. Alexandre precisa, portanto, de uma justificação mais forte para poder fundamentar sua doutrina da transitividade da responsabilidade.

Uma estratégia que Alexandre igualmente adota consiste em assinalar que as disposições provêm da realização repetida de atos, estes atos sendo realizados

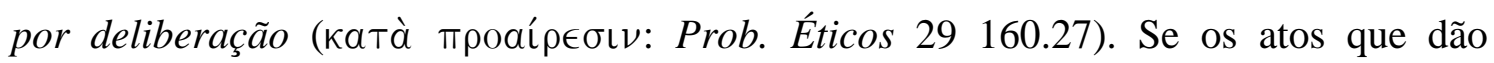
origem às disposições são atos que, em um sentido moral relevante, eu próprio escolhi, e que estavam assim em meu poder fazer ou não fazer, então parece plausível dizer que as disposições que daí se geraram são, em um sentido moral relevante, minhas disposições, das quais sou agora responsável, inclusive dos atos que dela se engendram. O cerne desta estratégia consiste em pôr em relevo que, se os atos que geraram as disposições foram atos que realizei com base em uma escolha deliberada, então sou 
plenamente responsável por eles, e essa plenitude de responsabilidade serviria como que garantia do fato de continuar sendo responsável pelos atos que produzo quando não sou mais capaz de agir diferentemente por agir com base em disposições bem estabelecidas. Esta estratégia não esconde, porém, sua dificuldade, pois ela é certamente excessiva. Na ética aristotélica, as disposições se engendram com base na repetição de atos voluntários, e atos voluntários não necessariamente requerem a intervenção da escolha e da deliberação. Alexandre é bem consciente disso, pois ele distingue claramente os atos que escolho, e que estão assim em meu poder de ocorrer ou não ocorrer, e os atos voluntários: todo ato por escolha é voluntário, mas nem todo ato voluntário ocorre por escolha. A noção de estar em meu poder, que abre a ação à possibilidade dos contrários, está fundada na deliberação que o agente faz a respeito dos meios de que dispõe, e, nesta medida, tem seu destino conectado ao de escolha deliberada. Alexandre reafirma tal posição expressamente em De fato XIV: “voluntário e estar em nosso poder não é a mesma coisa. Voluntário é o que ocorre com base em um assentimento não forçado; estar em nosso poder é o que ocorre com um assentimento conforme a razão e o juízo”

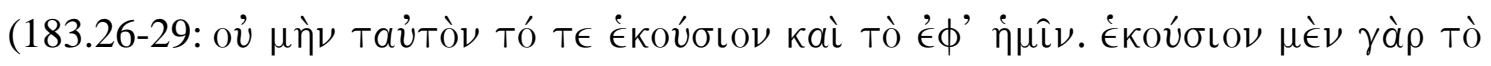

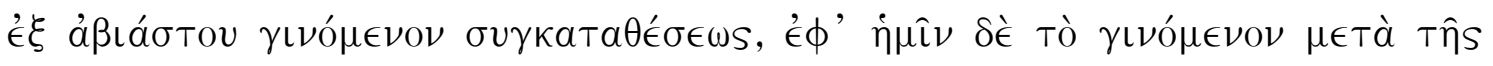

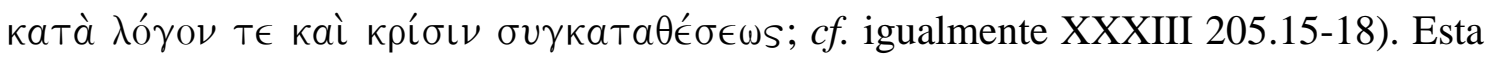
estratégia, portanto, exige demais do voluntário, que pode ocorrer, e assim gerar disposições, sem envolver escolhas deliberadas.

Em sua defesa, contudo, poder-se-ia alegar que, na Ethica Eudemia, Aristóteles faz confluir as noções de estar em nosso poder e voluntário, na medida em que se propõe a definir o voluntário como o que, não sendo forçado, ocorre por

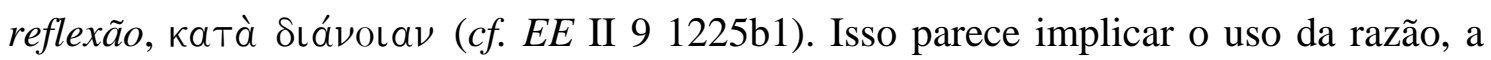
saber, a razão prática, por conseguinte a abertura aos contrários, o que é justamente posto em realce na noção de estar em nosso poder. Não surpreende assim que a definição de voluntário presente no livro V da Ethica Nicomachea combine ambas as

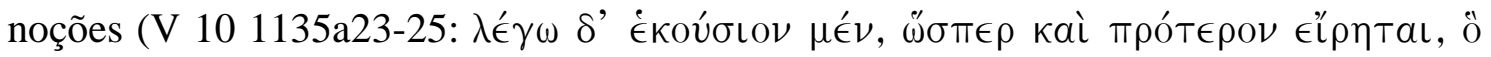

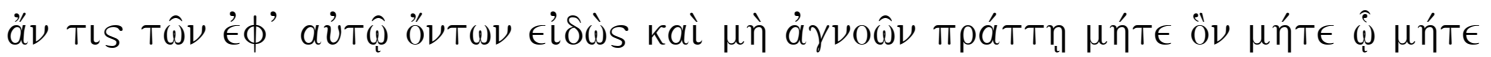

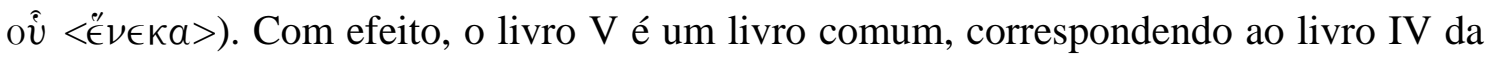


Ethica Eudemia, e há fortes razões para se crer que os livros comuns partilhem do mesmo ambiente conceitual que a Ethica Eudemia. A passagem de EN V 10 remete a algo dito anteriormente, mas não há, na Ethica Nicomachea, nenhuma passagem que conecte a noção de agir voluntariamente à condição de estar em nosso poder; isso ocorre somente na Ethica Eudemia. ${ }^{4}$ Na Ethica Nicomachea, ao contrário, a condição de estar em nosso poder implica a abertura aos contrários e, nesta medida, está diretamente associada à noção de escolha deliberada, pois é mediante a introdução da razão prática deliberativa na ação que o homem (e somente o homem) pode escolher entre os contrários. Na Ethica Nicomachea, o voluntário requer unicamente que quem age discrimine as circunstâncias em que se produz a ação e que o princípio da ação esteja nele; ora, isso é satisfeito igualmente pelos animais, sem que se diga que está no poder também dos animais agir ou deixar de agir. A Ethica Nicomachea define assim o voluntário visando a incluir nele também o que faz o animal, o que, ao que tudo indica, alarga o domínio denotado pela definição eudemiana, a qual, ao correlacionar voluntário e estar em nosso poder, restringia o agir voluntário ao homem (à exclusão

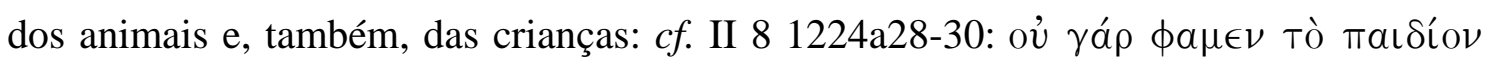

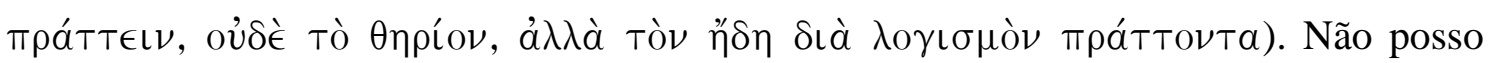
entrar aqui em mais detalhes sobre as divergências entre as duas obras no que toca à definição do voluntário, entre outras coisas, mas talvez nem seja mesmo preciso. Com efeito, qualquer que seja esta relação, o fato é que a Ethica Eudemia inclui a noção de estar em nosso poder na definição de voluntário na medida em que pensa esta última

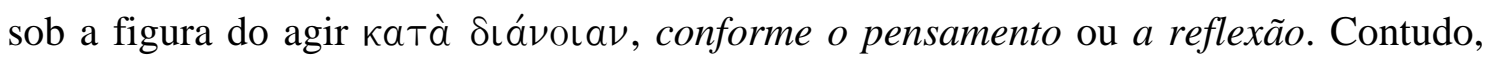
ela o faz no expresso contraste com agir conforme a escolha deliberada, кaтà

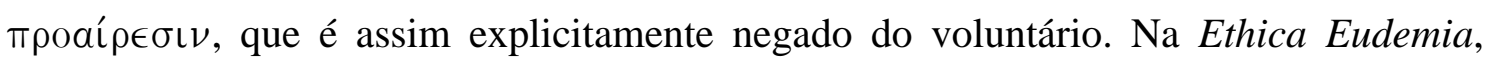

\footnotetext{
${ }^{4}$ R.-A. Gauthier remete a EN III 3 1111a22-24, argumentando que "ici et là, deux conditions sont requises pour qu'un acte soit fait de plein gré: d'une part, qu'il soit en notre pouvoir (ou que son principe soit à l'intérieur du sujet), et, d'autre part, que l'on agisse sciemment" (L'Ethique à Nicomaque, Peeters 2002, II 1 p. 398). Porém, justamente, na EN não comparece a noção de estar em nosso poder, mas somente a de o princípio estar no agente. Stewart é mais cauteloso, remetendo a $E E$ II 9, assim como a $E N$ III 3; R. Bodéüs, autor da mais recente tradução para o francês, remete, como Gauthier, a EN III 3 1111a22-24, embora o termo aí não compareça (Ethique à Nicomaque, GF Flammarion 2004, p. 265).
} 
para obter a definição do voluntário, Aristóteles apresenta inicialmente três possibilidades: o desejo, a escolha deliberação e o pensamento, e obtém sua definição mediante a exclusão dos dois primeiros casos. Assim, mesmo que concedamos a aproximação com o pensamento (o que de fato ocorre na Ethica Eudemia, mas é deixado de lado na Ethica Nicomachea), ainda assim permanece exagerado requerer do involuntário a satisfação da condição de proceder por escolha deliberada, pois a noção de pensamento só figura na definição do voluntário por ter sido explicitamente negada a de escolha deliberada. ${ }^{5}$

O que sugere Alexandre parece ser, antes do que uma solução, o sintoma de uma dificuldade. Com efeito, para funcionar, é preciso mostrar que a deliberação ou escolha deliberada institui de fato um campo aberto às alternativas. Mais ainda, Alexandre tem de mostrar isso de tal modo que, quando o agente tiver suas disposições, ele não poderá mais estar genuinamente diante de alternativas - mesmo que o prudente possa ser descrito corretamente como aquele que delibera bem. De algum modo, pelo menos enquanto não tiver suas disposições, o agente, ao escolher como agirá, pode tanto fazer como não fazer algo, e isso de modo genuíno. Alexandre costuma queixar-se que é evidente que a deliberação nos põe genuinamente diante de alternativas; um de seus argumentos favoritos consiste em reclamar que a natureza nos deu a aptidão a deliberar e que ela não faz nada em vão, o que nos deveria levar a concluir que estamos freqüentemente diante de alternativas reais entre fazer e deixar de fazer. Porém, ele sabe que não pode simplesmente supor que, quando há deliberação, alternativas estejam de fato disponíveis ao agente e não sejam, por exemplo, uma mera ilusão sua, ou mesmo que, embora o agente seja capaz de deliberar, ele está imerso em um determinismo moderado, no qual certas coisas ocorrem supondo uma co-causalidade da sua parte, que opera em função de sua natureza, o que não é incompatível com procedimentos deliberativos de decisão, pois mediante tais procedimento não é negado um sistema

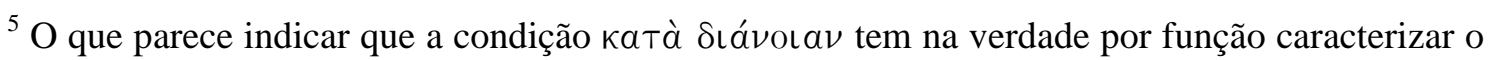
fato do princípio estar no agente a título de representado ou figurado conceitualmente pelo agente, sem ainda implicar a escolha deliberada, o que, porém, já limitaria o voluntário àqueles que têm razão (o homem), à exclusão dos que não a têm (os animais) ou que ainda não se servem dela (as crianças).
} 
geral determinado da natureza (ao contrário, ele é simplesmente tornado mais eficaz graças à faculdade de bem deliberar a título de propriedade natural que certos animais têm para realizar do melhor modo os fins que buscam).

Alexandre escreve em Mantissa 23 que a liberdade ensejada pela deliberação não é estabelecida de modo irrefletido nem seu enunciado é um postulado

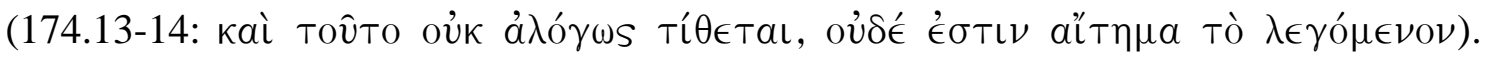
Há, pois, uma prova. Como, porém, funciona ela? O terreno fica aqui escorregadio. Podemos encontrar certas indicações no que se poderia chamar de tratado da faculdade impulsiva ou desiderativa, que se encontra nas páginas 71.21-80.15 do De Anima de Alexandre. Adotando a ordem aí proposta para o estudo do movimento nos animais,

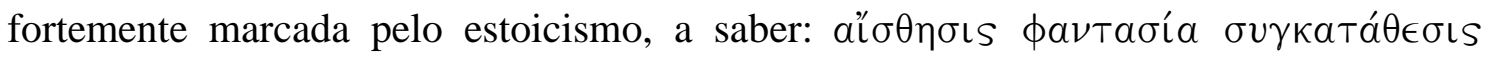

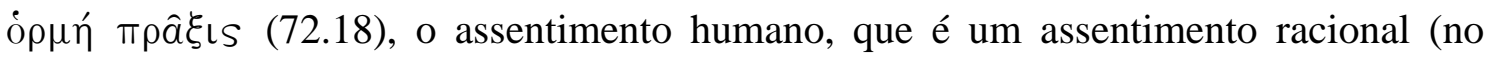
caso, deliberativo, por ser prático), está aberto aos contrários e, neste sentido, está em nosso poder agir ou não agir. O assentimento acerca de coisas simples, isto é, a respeito de ser ou não ser, não está em nosso poder, mas se segue à impressão e à imaginação; contudo, o assentimento relativo ao que deve ser feito e ao que não deve ser feito, de

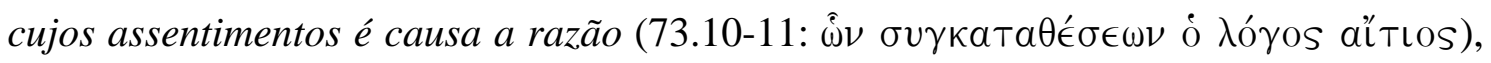
está em nosso poder, no sentido relevante aqui, a saber: o agente pode tanto fazer como não fazer. Em certo sentido, isto parece plausível: supondo que todos partilhem a mesma faculdade de inferência e que saibam todos aplicá-la corretamente no domínio prático (a despeito do variegado de fins e de outras circunstâncias que tornam freqüentemente complexa a aplicação da razão no domínio prático), pode-se supor com muita razoabilidade que um agente, que tem uma dada natureza, dará tal assentimento a certo objeto da imaginação, enquanto outro, que tem, porém, uma outra natureza, dará um outro assentimento a este mesmo objeto. Em que sentido, porém, se pode falar genuinamente de uma escolha aberta aos contrários no que concerne ao mesmo agente, de modo que se pode fazer A, então ele tem também, em um sentido relevante, de poder fazer não-A? No seu clássico trabalho sobre a filosofia helenística, Long \& Sedley escreveram que: 
[P]ode ser tentador supor que um agente é responsável somente quando ele poderia ter agido diferentemente no sentido forte que nada, interno ou externo a ele, predeterminou a ação que escolheu no momento. Para os estóicos, isso é ininteligível. Não somente vai contra as leis lógicas e metafísicas fundamentais na qual se funda a doutrina do destino, mas também requer que as pessoas sejam capazes de agir contrariamente ao seu caráter moral. ${ }^{6}$

A terminologia que usa Alexandre é seguramente estóica, mas sua perspectiva se inscreve no aristotelismo, para o qual é condição da responsabilidade o fato do agente ter podido agir diferentemente, e isso em um sentido genuíno, isto é, não no sentido que poderia ter tido uma outra natureza, o que o teria então feito agir diferentemente, mas no sentido em que, aqui e agora, ele tanto pode fazer como deixar de fazer tal coisa. Contudo, Alexandre partilha com os estóicos um tipo de dramatização do caráter, de modo que o agente, uma vez adquiridas as disposições morais, não pode mais agir diferentemente. Como pode então aderir à tese forte aristotélica que a deliberação instaura um campo de indeterminação a respeito do que fará relativamente a cada ação? No De fato, Alexandre não parece senão poder recorrer a argumentos do tipo: o determinismo torna vã a deliberação; ora, a natureza nos fez aptos a deliberar e a natureza não faz nada em vão. Argumentos deste tipo são insuficientes para eliminar a possibilidade da ilusão decisória que a deliberação criaria em nós, bem como em nada impossibilitam a adoção de um determinismo conjugado com atitudes próprias ao agente em função de sua natureza. Este último ponto é decisivo. Com efeito, os estóicos também falam do que depende de nós, isto é, daquilo que, em acordo com nossa natureza, não se realizará se não agirmos em uma certa direção (para o que a razão prática, também sob a forma deliberativa, pode ser muito útil). Porém, Alexandre está perfeitamente consciente que o '̇ $\phi^{\prime} \dot{\eta} \mu \hat{\imath} \nu$, assim concebido, significa propriamente aquilo que ocorre com nossa concorrência, algo que ocorreria como que através de nós, sem, porém, implicar uma efetiva escolha entre contrários. A razão disso é que os estóicos eliminam a abertura genuína aos contrários em uma dada ação, embora certas coisas não possam ocorrer sem a participação ou concorrência do agente. Alexandre

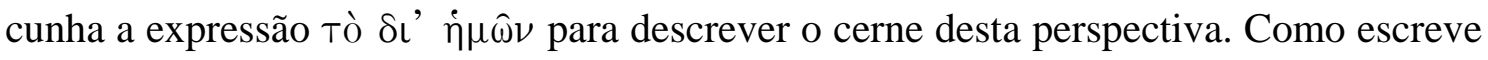

\footnotetext{
${ }^{6}$ A. Long \& D. Sedeley, The Hellenistic Philosophers, CUP 1987 (1995), vol. 1 p. 393.
} 
no De fato XII, “eliminando, pois, o poder que o homem tem de escolher e realizar os contrários, eles dizem que o que está em nosso poder é o que ocorre através de nós”

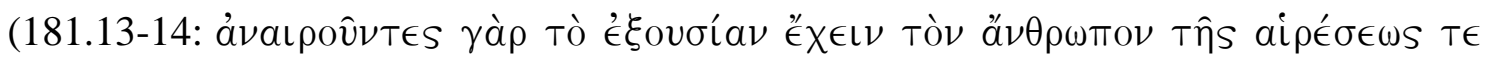

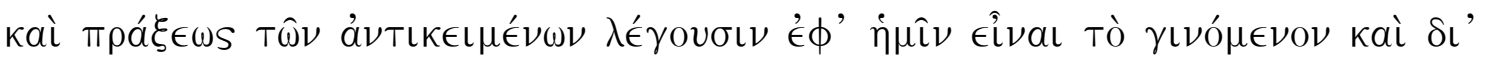
$\dot{\eta} \mu(\hat{\omega} \nu)$. A expressão $\delta \mathrm{s}$ ' $\dot{\eta} \mu \hat{\omega} \nu$ provavelmente não faz parte do vocabulário dos deterministas, mas provém da reflexão que Alexandre faz sobre a que ele pode se referir em um meio determinista. ${ }^{7}$ Nesta perspectiva, ela capta perfeitamente bem, aos olhos de Alexandre, a dificuldade de introduzir uma noção genuína de abertura aos contrários. No entanto, em De fato XXVIII, capítulo no qual Alexandre menciona a objeção segundo a qual não somos senhores do modo como nascemos nem, por conseguinte, do modo como as coisas aparecem a nós, de sorte que não temos a possibilidade de escolher genuinamente entre agir assim ou não assim de modo a poder ser pelo menos em parte responsáveis pela aquisição de nosso caráter, ${ }^{8}$ Alexandre tem somente a replicar que uma tal doutrina implicaria que o homem é o pior de todos os animais

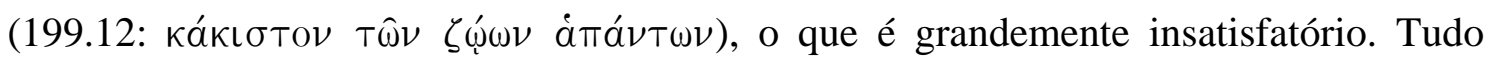
indica que Alexandre é bastante preciso ao identificar o cerne da dificuldade, mas não parece dispor de uma resposta suficientemente forte para reviver o aristotelismo que reivindica.

No Mantissa há duas reflexões sobre a noção de estar em nosso poder com teses, porém, fortemente dissonantes. A segunda, o tratado de número 23, é geralmente considerada como estando na linha do De fato, enquanto a primeira, de número 22, precisamente por aparentemente destoar desta linha, é vista como tendo problemas de autoria. Penso, no entanto, que temos boas razões para revisitar com maior atenção o tratado 22, pois talvez seja unicamente aí que encontraremos uma explicação para o fato da deliberação, pelo menos em certo momento, ser fonte de indeterminação. Vejamos inicialmente, porém, a doutrina que o tratado 23 defende,

\footnotetext{
${ }^{7}$ Como observou R. Sharples, Alexander of Aphrodisias On Fate, Duckworth 1983, p. 143.

${ }^{8}$ O problema, como se sabe, foi também formulado por Aristóteles em EN III 7 1114a31 - b12. Esta passagem de Aristóteles é analisada mais minuciosamente por Alexandre nos Problemas Éticos XXIX, mas não há aí nenhuma tese conceitualmente inovadora. Sobre esta passagem, remeto à análise que propus em Estudos de Ética Antiga (Discurso 2007) pp. 301-325.
} 
normalmente aceito como o mais em linha com o resto da obra de Alexandre. Neste ensaio, é assumida a tese segundo a qual havendo um mesmo fim e ocorrendo as mesmas circunstâncias, o homem não poderia senão agir de mesmo modo. No entanto, é argumentado que, como há vários fins com vistas aos quais é feita a escolha do que

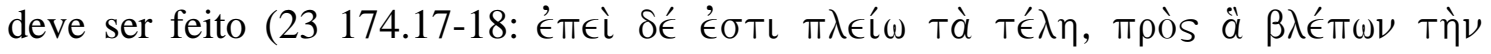

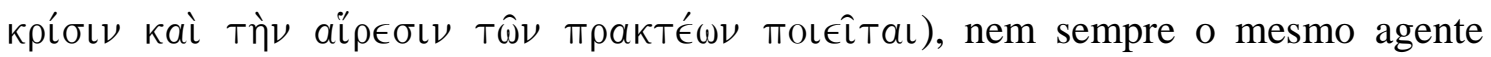
segue a mesma decisão, pois ora o fim é o prazer, ora o útil, ora o belo. O argumento surpreende, pois tudo o que ele é capaz de introduzir é uma diversidade no fim que conduz a deliberação (ora o belo, ora o útil, ora o prazeroso), mas, dado um fim e dadas as mesmas circunstâncias, não parece haver nenhum espaço de liberdade para que o agente venha a agir diferentemente. Como Aristóteles insiste, e Alexandre aceita isso sem contestação, que só deliberamos sobre os meios, nunca sobre os fins, variações sobre os fins não acarretariam nenhum espaço, por si só, da possibilidade do agente fazer ou deixar de fazer em função da deliberação que leva a cabo a partir do fim. Com efeito, o agente ele próprio não dispõe de nenhum domínio sobre o modo como o fim lhe aparece - ora como o prazer, ora como o útil, ora como o belo. Mesmo assim, é com base neste mesmo recurso - a diversidade de fins: o belo, o útil, o prazeroso - que se busca também resolver a objeção segundo a qual se age sempre em função do que nos aparece como melhor, mas não temos controle do modo como as coisas aparecem a nós (objeção que é mencionada também no De fato XXVIII e volta a ser objeto de exame nos Problemas Éticos XXIX): a idéia aqui, no Mantissa 23, é que o ajuizar a respeito da imaginação - que está em jogo no assentir ou não a ela - está em estreita dependência com os diversos fins que temos, o que faria variar o assentimento (174.24-27). Novamente, tudo o que este argumento garante é uma diversidade de comportamentos do mesmo agente com base em uma variedade de fins, tais como lhe aparecem, mas não uma genuína escolha de, dado um fim, poder dar ou deixar de dar o assentimento à imaginação em função de uma deliberação racional a seu respeito. Ainda uma vez, Alexandre simplesmente reafirma que, pela deliberação, um agente pode, nas mesmas circunstâncias, deixar de fazer o que fez e escolher o oposto; um indício disso seria o fato que, ao menos, alguém pode querer mostrar alguma vez que a escolha não é 
necessitada e se dispor a fazer isso, para o que é sensato escolher o que não lhe aparece

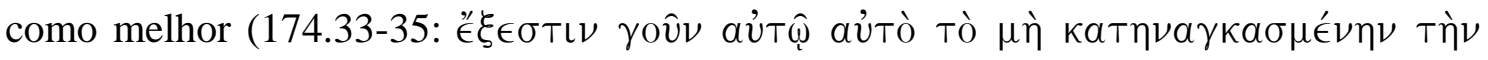

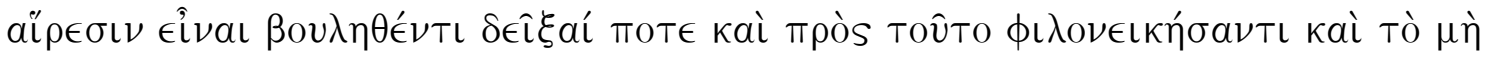

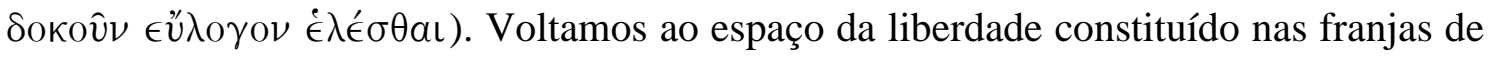
uma certa bizarria do agente, o que já havia sido mencionado no De fato XXIX a respeito do prudente que age diferentemente para assim tornar falsa uma predição a respeito de seu comportamento, mesmo que ronde este espaço, de modo mais claro aqui do que no De fato, o espectro de uma naturalização também do desejo de se mostrar livre, dada uma certa natureza do agente.

O tratado 23 do Mantissa está assim em linha com o que vemos sobretudo no De fato e, assim como este, deixa o problema de uma deliberação genuína sem resposta. O tratado 22 aportará, porém, uma solução que me parece mais conseqüente. A idéia que guia este tratado é uma simetria entre a falha e o não ser da matéria, que explica por que, no mundo natural, é sempre possível que algo ocorra diferentemente, embora costume ocorre nas mais das vezes de um certo modo, e a

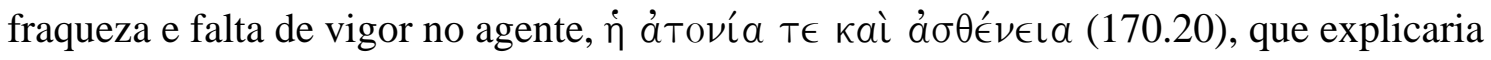
por que, nas mesmas circunstâncias, o agente não age do mesmo modo. Segundo o argumento, prova-se que há um movimento não causado se se mostra que, nos seres

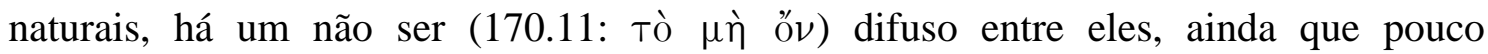
numeroso, que faz com que não haja uma causa própria, mas meramente acidental. $\mathrm{O}$

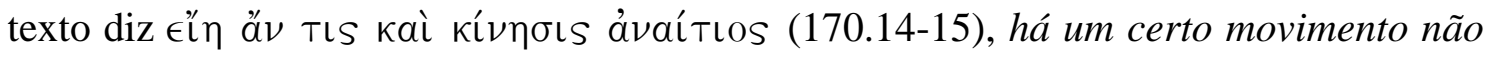
causado, mas quer com isso pensar não que há movimentos simplesmente sem causa, mas sim que não há causa própria de certos movimentos, e sim causa acidental. O certo não qualifica movimento somente, mas movimento não causado: é somente em certo sentido que ele não é causado. Não se trata, por conseguinte, de mostrar que há eventos sem causa, mas que sua causa é acidental. Um pouco adiante, em 171.9, com efeito, é introduzida a expressão causa acidental para o caso em que algo ocorra não por uma causa finalizada ou própria; é explicitado então que algo é dito ter ocorrido sem causa porque não tem causa própria (171.14). É neste momento que é introduzida a simetria entre mundo e ação: quando esta não-causa própria, ou causa acidental, ocorre no 
mundo, dá lugar ao acaso ou fortuna; quando ocorre em nós, dá lugar ao que depende de

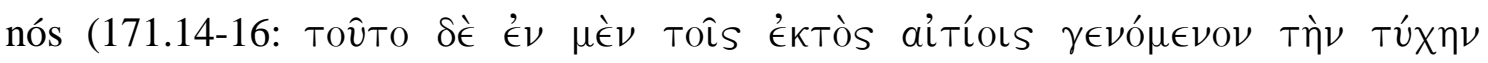

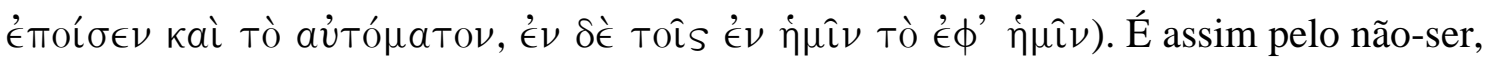
fraqueza ou atonia, que penetram na natureza e no mundo humano, de modo difuso, mas pouco numeroso, as coisas por acidente, as por fortuna e o que é dito propriamente

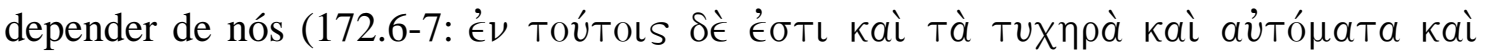

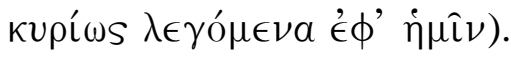

À primeira vista, esta doutrina é dificilmente conciliável com o que diz o tratado 23 e o De fato, mas isso somente à primeira vista. Alexandre aceita a tese segundo a qual, quando o agente tem suas disposições formadas, ele não pode mais agir diferentemente. Para preservar a responsabilidade de suas ações, Alexandre recorreu à tese da transitividade: embora não possa mais agir diferentemente, ele é responsável hoje pelo que faz porque foi responsável, no passado, pelas ações que geraram suas disposições. Quando não tinha disposições, podia agir diferentemente; agora que as tem, não pode mais agir de outro modo. Foi preciso acentuar o elemento de escolha em sua formação, mesmo ao preço de atribuir ao voluntário algo que não necessariamente tem, mas que nada impede que tenha. Mas como podia escolher diferentemente? Segundo o tratado 22, se nos ativermos às escolhas feitas por hábito (isto é, aquelas que faz o agente que tem as disposições formadas), nada do que faz está genuinamente aberto aos contrários, sendo antes, propriamente, coisas que ocorrem $\delta \iota^{\prime} \dot{\eta} \mu \hat{\omega} \nu$, como o próprio Alexandre reconhecera a respeito da noção estóica. No caso da formação do agente, às escolhas comandadas pela natureza ou pela educação, também o que é suposto ser '€申' $\dot{\eta} \mu \hat{\imath} \nu$, no seu sentido forte, é propriamente algo que ocorre através de nós, $\delta \iota^{\prime}$ iं $\mu \hat{\omega} \nu$ (22 171.8). Aparentemente, não há nenhum espaço para aquela liberdade genuína quanto aos contrários: ou o agente já está formado, e não pode mais agir diferentemente, ou está em formação, mas, neste caso, ou bem segue sua natureza, sobre a qual não tem controle, ou obedece à educação que lhe foi impingida, eventualmente alterando suas tendências naturais - mas tampouco neste caso há algo de próprio do agente. É aqui que jaz o elemento decisivo: é preciso encontrar na formação do agente um momento em que possa agir diferentemente (o que vai garantir a transitividade da responsabilidade), 
sem que o poder agir diferentemente se transmita à fase madura, mas somente a responsabilidade. Porém, nem os dotes naturais nem a educação podem ocupar este espaço, pois não há nada aí de próprio dele, pelo menos não no sentido forte que Alexandre ainda quer emprestar à noção aristotélica de estar em nosso poder. Aparentemente, a dificuldade é herdada de Aristóteles, pois se Aristóteles resolveu o problema de agir diferentemente do modo como propõe Alexandre, a saber, recuando o ponto para o período de formação do agente, pode-se repetir, com Robert Sharples, que

[E]ste argumento, todavia, somente leva o problema para o passado, até que se chegue às influências em nossa infância - dotes naturais, treino e educação -, das quais dificilmente podemos ser vistos como responsáveis. ${ }^{9}$

Tendo recuado à formação do agente, Alexandre, embora insista que o estar em nosso poder está unicamente presente nos seres que agem com base em um

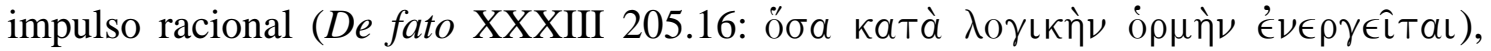
não tem como dar espessura ao uso da razão quando ela está estiolada entre o que a natureza deu ao agente e o que a educação lhe acrescentou. Tudo isso - natureza ou educação - é mais propriamente $\delta \iota^{\prime} \dot{\eta} \mu \hat{\omega} \nu$ do que '€́ ${ }^{\prime} \dot{\eta} \mu \hat{\imath} \nu$. Quando o agente tiver a razão bem equipada, terá também suas disposições - e novamente, segundo nosso texto, ele estará antes no $\delta \iota^{\prime} \dot{\eta} \mu \hat{\omega} \nu$ do que no $\phi^{\prime} ’ \dot{\eta} \mu \hat{\imath} \nu$. As escolhas só serão em um sentido relevante escolhas do agente quando aquela falha, a fraqueza ou atonia, perturbar o regime instaurado pela natureza e pela educação e provocar algo próprio àquele agente. Simetricamente à natureza, que ocorre de outro modo raramente, em função da falha que a matéria inevitavelmente traz, também o homem, em seu período de formação, agirá diferentemente por conta de uma fraqueza ou atonia. Tal fraqueza pode ainda persistir na vida madura, mas ali persistirá sob forma residual. O que importa é que ela explica, de modo surpreendente, como o homem pode agir diferentemente em seu período de formação, o que transmite a responsabilidade para o período em que, disposicionalmente determinado, ele não pode mais agir diferentemente.

É esta uma boa solução? Não estou seguro. Ela substitui um paradoxo (o de não poder mais agir diferentemente quando justamente nos consideramos por

\footnotetext{
${ }^{9}$ R. Sharples, op. cit., pp. 6-7.
} 
excelência responsáveis do que fazemos) por um outro paradoxo, mais radical (o de atribuir a potência de agir diferentemente, base de toda responsabilidade, a algo análogo à falha que a matéria introduz nos seres sensíveis). O erro e o fracasso são em última instância a garantia de nossa liberdade. O que gostaria, porém, de ter mostrado é que o tratado 22 do Mantissa apresenta a resposta mais conseqüente, ainda que não inteiramente coerente, da posição em que se colocou Alexandre. A resposta não é inteiramente coerente porque a possibilidade de agir diferentemente estava fundada em Aristóteles na potência racional dos contrários, mas fica reduzida aqui, em Alexandre, à expressão de uma falha formativa. Ela é, porém, a mais conseqüente, porque todas as outras soluções, inclusive a proposta no tratado 23, não reconhecem a gravidade do problema, que esta última pelo menos vislumbra em sua formulação, ao igualar, em seu recuo ao período de formação, os dotes naturais e a educação à natureza $\delta \iota^{\prime} \dot{\eta} \mu \omega \hat{\nu} \nu$ das disposições do agente maduro, nas quais não é o caso poder genuinamente agir de outro modo naquilo que tem relevância moral, portanto nas quais o '́㇒' ' $\dot{\eta} \mu \hat{\imath} \nu$ se torna propriamente um $\delta \iota^{\prime} \dot{\eta} \mu \hat{\omega} \nu$.

Referências Bibliográficas

BODEUS, R. Ethique à Nicomaque, GF Flammarion 2004.

GAUTHIER, R.-A. L'Ethique à Nicomaque, Peeters 2002.

IRWIN, T. Nicomachean Ethics, Hackett 1985.

LONG, A. \& SEDLEY, D. The Hellenistic Philosophers, Cambridge 1987.

SHARPLES, R. Alexander of Aphrodisias: On Fate, Duckworth 1983.

ZINGANO, M. Estudos de Ética Antiga, Discurso Editorial 2007. 